\title{
Genetic diversity analysis of Thai indigenous chickens based on complete sequences of mitochondrial DNA D-loop region
}

\author{
Piyanat Teinlek $^{1,2}$, Kannika Siripattarapravat ${ }^{1,2,3}$, and Chanin Tirawattanawanich ${ }^{1,2,4, *}$
}

* Corresponding Author: Chanin Tirawattanawanich Tel: +66-2-579-7538, Fax: +66-2-579-7538,

E-mail: fvetcnt@ku.ac.th

${ }^{1}$ Center for Agricultural Biotechnology, Kasetsart University, Kamphaeng Saen Campus, Nakhon Pathom 73140, Thailand

${ }^{2}$ Center of Excellence on Agricultural Biotechnology (AG-BIO/PERDO-CHE), Bangkok 10900, Thailand ${ }^{3}$ Department of Pathology, Faculty of Veterinary Medicine, Kasetsart University, Bangkok 10900, Thailand

${ }^{4}$ Department of Physiology, Faculty of Veterinary Medicine, Kasetsart University, Bangkok 10900, Thailand

ORCID

Piyanat Teinlek

https://orcid.org/0000-0002-1198-4741

Kannika Siripattarapravat

https://orcid.org/0000-0002-5847-2356

Chanin Tirawattanawanich

https://orcid.org/0000-0002-1570-4380

Submitted Aug 17, 2017; Revised Oct 2, 2017; Accepted Jan 9, 2018
Objective: Complete mtDNA D-loop sequences of four Thai indigenous chicken varieties, including Pra-dhu-hang-dam (PD), Leung-hang-khao (LK), Chee (CH), and Dang (DA) were explored for genetic diversity and relationships with their potential ancestor and possible associates to address chicken domestication in Thailand.

Methods: A total of 220 complete mtDNA D-loop sequences of the four Thai indigenous chicken varieties were obtained by Sanger direct sequencing of polymerase chain reaction amplicons of 1,231 to 1,232 base pair in size. A neighbor-joining dendrogram was constructed with reference complete mtDNA D-loop sequences of Red Junglefowl (RJF) and those different chicken breeds available on National Center for Biotechnology Information database. Genetic diversity indices and neutrality test by Tajima's D test were performed. Genetic differences both within and among populations were estimated using analysis of molecular variance (AMOVA). Pairwise fixation index $\left(\mathrm{F}_{\mathrm{ST}}\right)$ was conducted to evaluated genetic relationships between these varieties.

Results: Twenty-three identified haplotypes were classified in six haplogroups (A-E and H) with the majority clustered in haplogroup A and B. Each variety was in multiple haplogroups with haplogroups $\mathrm{A}, \mathrm{B}, \mathrm{D}$, and $\mathrm{E}$ being shared by all studied varieties. The averaged haplotype and nucleotide diversities were, respectively 0.8607 and 0.00579 with non-significant Tajimas $D$ values being observed in all populations. Haplogroup distribution was closely related to that of RJF particularly Gallus gallus gallus (G. g. gallus) and G. g. spadiceus. As denoted by AMOVA, the mean diversity was mostly due to within-population variation $(90.53 \%)$ while between-population variation (9.47\%) accounted for much less. By pairwise $\mathrm{F}_{\mathrm{ST}} \mathrm{LK}$ was most closely related to $\mathrm{DA}\left(\mathrm{F}_{\mathrm{ST}}=0.00879\right)$ while $\mathrm{DA}$ was farthest from $\mathrm{CH}\left(\mathrm{F}_{\mathrm{ST}}=0.24882\right)$.

Conclusion: All 4 Thai indigenous chickens are in close relationship with their potential ancestor, the RJF. A contribution of shared, multiple maternal lineages was in the nature of these varieties, which have been domesticated under neutral selection.

Keywords: Thai Indigenous Chicken; Mitochondrial DNA D-loop; Genetic Diversity; Domestication

\section{INTRODUCTION}

It is widely believed that domestic chickens are descendants of the red junglefowl (RJF) as firstly indicated by Darwin [1] in the comparisons of morphology and production among Gallus species. Supportive molecular genetic evidence was later reported with a suggestion of monophyletic origin theory in which Gallus gallus gallus (G. g. gallus), those endemic to Southeast Asia, potentially serves as the sole ancestor of domestic chicken [2,3]. Such information has some limitations as being extracted from small sample sizes of partial mtDNA D-loop sequences of 400 base pairs (bp), even though supportive evidences on the Southeast Asian origination of domestic chickens has been published [4]. Complete sequences of mtDNA D-loop region of Japanese indigenous chickens were later investigated for more 
clarification of phylogenetic relationships, maternal origin and route of introduction into Japan in which genetic derivation of Chinese and Korean chickens from Southeast Asia were defined [5]. On the other hand, some researchers suggested the possibility of multiple maternal origins and multiple domestications of domestic chickens from different regions, including India, Southwest China and Southeast Asia [6-10]. Besides G. g. gallus, genetic relationships between Indian domestic chickens and G. g. spadiceus and G. g. murghi have also been reported [9].

Regarding mtDNA D-loop information of Southeast Asian chickens, Indonesian indigenous chickens have been reported to scatter in five clusters, being associated to reference sequences from India, China and Indonesia [11]. Laotian indigenous chickens have also been found dispersed in five clades, having the majority in clades A and B of which locations of origin are believed to be Southeast Asian continent and China [12]. Vietnamese local chickens appear to be more diverse with 8 clusters which related to reference sequences of Indian, China and Southeast Asian origins [13]. These suggested that Southeast Asian indigenous chickens would have multiple maternal origins.

Molecular technology has the efficiency and accuracy in the genetic study among breeds of animals. The evolutionary rate of the mtDNA is about five to ten times faster than the nuclear genome due to the fact that mutation accumulates slowly in nuclear genes [14]. In addition, unlike the mtDNA with the presence of only maternal encoding genetic sequences, the nuclear genes represent the integrative genetic information derived from both parental sides in every generation, which could hide the history of individuals due to recombination. Tracking the history of particular nuclear DNA segment is therefore difficult. The complete sequence of mtDNA D-loop region has been successfully used in genetic study especially to determine phylogenetic relationships, including genetic distance and genetic variability within and among populations $[5,7,15]$. We therefore explored the complete mtDNA D-loop sequences of Thai indigenous chickens, including Pradhu-hang-dam (PD), Lueng-hang-khao (LK), Chee (CH), and Dang (DA) for genetic diversity and their relationships with other reference sequences of RJF and domestic chickens. We anticipated gaining significant evidences to better understand chicken domestication in Thailand, which is proposed to be the origin of chicken domestication [2].

\section{MATERIALS AND METHODS}

\section{Animals and sample collection}

The animal use protocol for this study was approved by Kasetsart University Institutional Animal Care and Use Committee. Four Thai indigenous chicken varieties, PD $(\mathrm{n}=80)$, LK ( $\mathrm{n}$ $=76), \mathrm{CH}(\mathrm{n}=34)$, and DA $(\mathrm{n}=30)$ from reference genetic stocks of the Department of Livestock and Development of Thailand were studied for their phylogenetic relationships based on complete mtDNA D-loop sequence. These populations have been maintained in a way to ensure that they are good representative genetic resources of each variety. The sequenced birds are parent stocks with no background family relationships among each individual. Blood samples were collected from brachial vein, using heparinized syringes. The samples were transferred on ice and kept frozen at $-40^{\circ} \mathrm{C}$ for later polymerase chain reaction (PCR) analysis.

\section{mtDNA D-loop amplification and sequencing}

Complete mtDNA D-loop region was specifically amplified by PCR using a primer pair of AV1F2: 5'-AGGACTACGGC TTGAAAAGC-3' and r2-3m: 5'-TGCTTAAGGTTA ATTAC TGCTG-3' [16]. The PCR reaction was performed in a $50 \mu \mathrm{L}$ reaction volume containing $25 \mu \mathrm{L}$ of $2 \times$ Phusion Blood Direct PCR Master Mix (Thermo Scientific, Waltham, MA, USA), $1 \mathrm{pmol} / \mu \mathrm{L}$ of each primer, $1 \mu \mathrm{L}$ of the whole blood sample and $22 \mu \mathrm{L}$ of $\mathrm{dH}_{2} \mathrm{O}$. The PCR was conducted in a thermal cycler (ARKTIK Thermal Cycler, Thermo Scientific, USA) with the conditions of $5 \mathrm{~min}$ initial denaturation at $98^{\circ} \mathrm{C}$, followed by 35 cycles, each consisting of $1 \mathrm{~s}$ denaturation at $98^{\circ} \mathrm{C}, 5 \mathrm{~s}$ annealing at $62^{\circ} \mathrm{C}$ and $1 \mathrm{~min}$ extension at $72^{\circ} \mathrm{C}$ cycle, and then final extension step at $72^{\circ} \mathrm{C}$ for $5 \mathrm{~min}$.

Each of the amplified product was mixed with SYBR Green (Thermo Scientific, USA) and $6 \times$ loading dye before subjecting to electrophoresis using $1 \%$ agarose gel in $0.5 \times$ Tris-acetateethylenediaminetetraacetic acid (TAE) buffer. The amplified products were visualized under ultraviolet light and purified using GeneJET PCR Purification Kit (Thermo Scientific, USA) before sending for direct sequencing on both strands at 1st BASE sequencing service (Singapore).

\section{Data analysis}

All sequences of 220 Thai indigenous chickens were viewed and edited. Multiple alignments and nucleotide sequence variations were conducted by ClustalW and BioEdit Sequence Alignment Editor, and identical sequences were considered as the same haplotype using DnaSP version 5.10 [17]. mtDNA $\mathrm{D}$-loop diversity indices, including the number of haplotype $(\mathrm{H})$, haplotype diversity $(\mathrm{Hd})$, and nucleotide $(\pi)$ diversity and Tajimass D test were estimated using DnaSP version 5.10 [17] and Arlequin version 3.5 [18]. To evaluate the sequence variation among and within the population, analysis of molecular variance (AMOVA) and pairwise fixation index $\left(\mathrm{F}_{\mathrm{ST}}\right)$ were computed using Arlequin version 3.5 [18].

Molecular phylogenetic analysis of complete D-loop sequences of Thai indigenous chickens and the nucleotide DNA databank from GenBank were conducted with molecular evolution genetic analysis version 6.0 [19]. An unrooted neighbor-joining (NJ) tree was constructed using Kimura 2-parameter 
model. Bootstrap values of the phylogenetic tree were estimated with 1,000 repetitions. Classifying haplotype into 13 haplogroups based on the mitochondrial genome study by Miao et al [7] with reference mtDNA sequences from the National Center for Biotechnology Information database as listed in Table 1 was performed. A sequence of Ceylon junglefowl (accession no. NC_007239) was chosen as outgroup.

\section{RESULTS}

\section{mtDNA D-loop sequence variability and population diversity}

The complete mtDNA D-loop sequences of the studied samples were found to be 1,231 to $1,232 \mathrm{bp}$ in length with a total number of 38 variable sites being identified (Table 2). All variable sites were in transition excepting position 391 that was in transversion and position 859 that was single nucleotide insertion/deletion. A total of 23 haplotypes were identified.

The diversity indices calculated for all experimental individuals are presented in Table 3 . A total number of haplotypes of all studied populations was 23, of which 16 (69.57\%) were singletons and only 7 (30.43\%) were shared between the Thai indigenous chickens. The highest number of haplotypes was found in LK representative population while the lowest number detected was in $\mathrm{CH}$ (13 and 4 haplotypes, respectively). The Hd of the Thai indigenous chickens was found ranging from 0.6399 to 0.8320 with the highest diversity being estimated in $\mathrm{PD}$ population and the lowest diversity in $\mathrm{CH}$ population. The averaged haplotype diversity of all population was approximately 0.8607 . The nucleotide diversity $(\pi)$ of the Thai indigenous chickens was between 0.00492 to 0.00563 that the highest value was observed in LK population and the lowest was in DA population. The average nucleotide diversity of the $220 \mathrm{mtDNA}$ D-loop sequences of Thai indigenous chicken populations was estimated to be 0.00579 . For all four varieties of Thai indigenous chicken, Tajima's D statistics for neutrality test was not significant $(\mathrm{p}>0.05)$.

In Table 4 , the genetic variation within and among population being quantified by AMOVA based on Kimura- 2 parameter distances is presented. Within population variation was found accounted for $90.53 \%$ of the genetic variation while differences among population generated a rather small contribution $(9.47 \%)$ to total genetic variation of the studied of Thai indigenous chicken populations. Differences among populations were highly significant $(\mathrm{p}<0.01)$.

\section{Genetic distance among Thai indigenous chicken populations}

Estimated values of pairwise population differentiation between the four Thai indigenous chickens according to $\mathrm{F}_{\mathrm{ST}}$ genetic distances were expressed in Table 5. Among the Thai indigenous chicken varieties, LK population was most closely

Table 1. Haplotype names and accession numbers of chicken complete mtDNA D-loop sequences used in this study

\begin{tabular}{|c|c|c|c|}
\hline Haplotype name & GenBank accession & Breeds/Varieties & Collection sites \\
\hline RJFspa_A & GU261695 & Red junglefowl (G. g. spadiceus) & China \\
\hline RJFspa_B & GU261704 & Red junglefowl (G. g. spadiceus) & Myanmar \\
\hline RJFspa_B & NC_007235 & Red junglefowl (G. g. spadiceus) & Laos \\
\hline RJFgal_C2 & AB007725 & Red junglefowl (G. g. gallus) & Unknown \\
\hline RJFspa_C3 & GU261716 & Red junglefowl (G. g. spadiceus) & Myanmar \\
\hline RJFmur_C3 & GU261707 & Red junglefowl (G. g. murghi) & India \\
\hline RJFgal_D1 & NC_007236 & Red junglefowl (G. g. gallus) & Philippine \\
\hline RJFban_D1 & NC_007237 & Red junglefowl (G. g. bankiva) & Indonesia \\
\hline RJFmur_E3 & GU261708 & Red junglefowl (G. g. murghi) & India \\
\hline RJFspa_F & GU261702 & Red junglefowl (G. g. spadiceus) & China \\
\hline RJFspa_F & GU261703 & Red junglefowl (G. g. spadiceus) & Myanmar \\
\hline RJFspa_G & GU261690 & Red junglefowl (G. g. spadiceus) & China \\
\hline RJFspa_W & GU261706 & Red junglefowl (G. g. spadiceus) & China \\
\hline RJFspa_X & GU261692 & Red junglefowl (G. g. spadiceus) & China \\
\hline RJFspa_Y & GU261693 & Red junglefowl (G. g. spadiceus) & China \\
\hline RJFjab_Z & GU261674 & Red junglefowl (G. g. jabouillei) & China \\
\hline ChiNC_C1 & GU261701 & Domestic chicken & China \\
\hline ChiNC_D2 & GU261683 & Domestic chicken & China \\
\hline IndNC_D3 & GU261697 & Domestic chicken & India \\
\hline LaoNC_E1 & AP003319 & Domestic chicken & Laos \\
\hline IndNC_E2 & HQ857209 & Domestic chicken & India \\
\hline ChiNC_H & GU261715 & Domestic chicken & China \\
\hline JapNC & AB268543 & Domestic chicken & Japan \\
\hline IndNC_I & GU261698 & Domestic chicken & India \\
\hline
\end{tabular}


Table 2. Sequence variation among mtDNA D-loop sequences of four varieties of Thai indigenous chicken

\begin{tabular}{|c|c|c|c|c|c|c|c|c|c|c|c|c|c|c|c|c|c|c|c|c|c|c|c|c|c|c|c|c|c|c|c|c|c|c|c|c|c|c|}
\hline \multirow{2}{*}{ Haplotype } & \multicolumn{38}{|c|}{ Polymorphic nucleotide sites } \\
\hline & 167 & 198 & 199 & 210 & 212 & 217 & 219 & 220 & 222 & 225 & 242 & 243 & 246 & 256 & 261 & 281 & 296 & 306 & 310 & 315 & 330 & 342 & 344 & 355 & 363 & 367 & 391 & 396 & 446 & 686 & 792 & 844 & 859 & 966 & 1075 & 1178 & 1214 & 1215 \\
\hline A01 & C & c & $\mathrm{T}$ & c & $G$ & $\mathrm{~T}$ & C & $\mathrm{T}$ & A & $\mathrm{T}$ & G & $\mathrm{T}$ & C & $\mathrm{T}$ & C & A & C & $T$ & C & C & C & A & A & $\mathrm{T}$ & C & $\mathrm{T}$ & C & $\mathrm{T}$ & C & G & G & $\mathrm{T}$ & * & G & A & $\mathrm{T}$ & C & $G$ \\
\hline A02 & & & . & . & & & & . & . & & & . & . & & & & . & . & & & . & . & & & & . & . & & & . & . & & * & & . & $c$ & & \\
\hline $\mathrm{A} 03$ & & & & & & & $\mathrm{~T}$ & & & & & & & & & & & & & & & & & & & & & & & & & & * & & & & & \\
\hline A04 & & & . & $\mathrm{T}$ & & & & . & . & & & . & . & & & & . & . & & & . & . & & & & . & . & & & . & . & & * & & . & & & \\
\hline B01 & $\mathrm{T}$ & & . & . & A & & & . & . & c & & . & $\mathrm{T}$ & . & & & . & . & & $\mathrm{T}$ & . & . & & & & . & . & & & A & A & . & * & & G & . & & A \\
\hline B02 & $\mathrm{T}$ & & . & . & A & & . & . & . & C & & . & $\mathrm{T}$ & . & & . & . & . & & $\mathrm{T}$ & . & . & . & & . & . & . & & & A & A & . & * & & . & . & . & A \\
\hline B03 & $T$ & & . & . & A & & . & . & . & c & & . & $\mathrm{T}$ & . & & . & $\mathrm{T}$ & . & & $\mathrm{T}$ & . & . & . & & . & . & . & & & . & A & . & * & & . & . & . & A \\
\hline B04 & $\mathrm{T}$ & . & & & A & & & & & C & . & & $\mathrm{T}$ & & & & & & & $\mathrm{T}$ & & & & & & & & & & & A & & * & . & & & & A \\
\hline B05 & $\mathrm{T}$ & . & & & A & & & & & C & . & & $\mathrm{T}$ & & . & & $\mathrm{T}$ & & & $\mathrm{T}$ & & & & . & & & & & . & & A & & c & & & & & A \\
\hline B06 & $\mathrm{T}$ & & & & A & . & & & & C & & & $\mathrm{T}$ & & . & & & & & $\mathrm{T}$ & & & & . & & & & & . & A & A & & c & & & & & A \\
\hline B07 & $\mathrm{T}$ & . & & & A & . & & & & C & & & $\mathrm{T}$ & & . & & $\mathrm{T}$ & & & $\mathrm{T}$ & & & & . & & & & C & . & & A & & C & & & & & A \\
\hline B08 & $\mathrm{T}$ & & & & A & . & & & & C & & & $\mathrm{T}$ & & . & & & & & $\mathrm{T}$ & & & & . & & & & & & & A & & C & & & & & A \\
\hline B09 & $\mathrm{T}$ & & . & . & A & & & . & . & C & & . & $\mathrm{T}$ & . & & & $\mathrm{T}$ & . & & $\mathrm{T}$ & . & . & & & & . & . & C & & . & A & . & * & & . & . & & A \\
\hline $\mathrm{C} 01$ & $\mathrm{~T}$ & & . & . & & & & . & . & $c$ & A & C & . & C & & $G$ & . & . & $\mathrm{T}$ & & . & G & & & $\mathrm{T}$ & C & . & & & . & . & . & * & & . & . & & \\
\hline D01 & $T$ & & . & . & . & & & . & . & C & & C & . & C & $\mathrm{T}$ & $G$ & . & C & $\mathrm{T}$ & & . & . & & & & . & . & & & . & . & & * & & . & . & & \\
\hline D02 & $\mathrm{T}$ & & . & & & & & . & & C & & C & . & C & $\mathrm{T}$ & $G$ & . & C & $\mathrm{T}$ & & . & $\mathrm{G}$ & & C & & . & . & & & . & . & & * & & . & & & \\
\hline D03 & $T$ & & & & & & & & & c & & $c$ & & $c$ & $\mathrm{~T}$ & $\mathrm{G}$ & & $c$ & $\mathrm{~T}$ & & & & & & & . & & & & . & & $c$ & * & & . & & & \\
\hline D04 & $\mathrm{T}$ & & . & . & . & & . & C & . & C & & C & . & C & $\mathrm{T}$ & $G$ & . & C & $\mathrm{T}$ & & . & . & $G$ & & . & . & . & & & . & . & . & * & & . & . & . & \\
\hline E01 & $\mathrm{T}$ & & . & . & . & c & . & . & . & $c$ & & $c$ & . & $c$ & $\mathrm{~T}$ & . & . & . & $\mathrm{T}$ & & . & . & . & & . & . & . & & $T$ & . & . & . & * & & . & . & $\mathrm{T}$ & \\
\hline $\mathrm{E} 02$ & $\mathrm{~T}$ & & . & . & . & c & . & . & $G$ & $c$ & & c & . & C & $\mathrm{T}$ & . & . & . & $\mathrm{T}$ & & $\mathrm{T}$ & . & & & . & . & . & & $\mathrm{T}$ & . & . & . & * & & . & . & $\mathrm{T}$ & \\
\hline E03 & $\mathrm{T}$ & & . & . & . & c & . & . & . & C & & c & . & C & $\mathrm{T}$ & . & . & . & $\mathrm{T}$ & & . & . & . & & . & . & . & & $\mathrm{T}$ & . & . & . & * & A & . & . & $\mathrm{T}$ & \\
\hline E04 & $\mathrm{T}$ & & . & . & . & $c$ & & . & . & $c$ & & c & . & c & $\mathrm{T}$ & . & . & . & $\mathrm{T}$ & & . & . & . & & . & . & A & & $\mathrm{T}$ & . & . & . & * & & . & . & $\mathrm{T}$ & \\
\hline H01 & $\mathrm{T}$ & $\mathrm{T}$ & C & & & . & & & & C & & C & & C & $\mathrm{T}$ & & & C & $\mathrm{T}$ & & & & & . & $\mathrm{T}$ & & $\mathrm{T}$ & & $\mathrm{T}$ & & & & * & & & & & . \\
\hline
\end{tabular}

The asterisk marks $\left({ }^{*}\right)$ mean nucleotide deletions and dots (.) refer to the same nucleotide with the first sequence.

Table 3. Diversity indices in four varieties of Thai indigenous chickens based on complete mtDNA D-loop sequences

\begin{tabular}{lccccc}
\hline Item & $\mathbf{n}$ & $\mathbf{H}$ & $\mathbf{H d}$ & $\boldsymbol{\pi}$ & Tajima's D (p-value) \\
\hline Pra-dhu-hang-dam & 80 & 11 & 0.8320 & 0.00545 & $1.31973(0.909)$ \\
Leun-hang-khao & 76 & 13 & 0.8179 & 0.00563 & $0.76207(0.818)$ \\
Chee & 34 & 4 & 0.6399 & 0.00503 & $1.37028(0.931)$ \\
Dang & 30 & 8 & 0.7816 & 0.00492 & $-0.00305(0.546)$ \\
Total & 220 & 23 & 0.8607 & 0.00579 & $0.40273(0.738)$ \\
\hline
\end{tabular}

n, number of sequence; $H$, number of haplotype; $H d$, haplotye diversity; $\pi$, nucleotide diversity.

Table 4. Analysis of molecular variance (AMOVA) of 220 complete mtDNA D-loop sequences of Thai indigenous chickens

\begin{tabular}{lcccccc}
\hline Source of variation & d.f. & Sum of squares & Variance components & Percentage of variation & $\mathbf{F}_{\text {ST }}$ & $p$-value \\
\hline Among population & 3 & 63.715 & $0.34629 \mathrm{Va}$ & 9.47 & - & - \\
Within population & 216 & 715.230 & $3.31125 \mathrm{Vb}$ & 90.53 & - \\
Total & 219 & 778.945 & 3.65754 & - & 0.09468 & 0.00 \\
\hline
\end{tabular}

d.f., degree of freedom; $F_{S T}$, fixation index.

$\mathrm{Va}$, among-population variance; $\mathrm{Vb}$, between-individual within-population variance.

related to $\mathrm{DA}$ population $\left(\mathrm{F}_{\mathrm{ST}}=0.00879\right)$ while further apart from $\mathrm{PD}$ and $\mathrm{CH}$ populations $\left(\mathrm{F}_{\mathrm{ST}}=0.07584\right.$ and 0.17277$)$. $\mathrm{DA}$ was least related to $\mathrm{CH}$ population $\left(\mathrm{F}_{\mathrm{ST}}=0.24882\right)$.

Table 5. Pairwise $F_{S T}$ between four varieties of Thai indigenous chickens based on mtDNA D-loop sequence

\begin{tabular}{lcccc}
\hline Item & PD & LK & CH & DA \\
\hline PD & 0.00000 & - & - & - \\
LK & 0.07584 & 0.00000 & - & - \\
CH & 0.02276 & 0.17277 & 0.00000 & - \\
DA & 0.12233 & 0.00879 & 0.24882 & 0.00000 \\
\hline
\end{tabular}

$\mathrm{F}_{\mathrm{ST}}$, fixation index; PD, Pra-dhu-hang-dam; LK, Leung-hang-khao; CH, Chee; DA, Dang.

\section{Phylogenetic analysis and haplotype distribution}

The phylogenetic analysis (Figure 1) revealed a classification of 23 haplotypes of the Thai indigenous chickens in 6 haplogroups (A-E and $\mathrm{H}$ ) of the 13-haplogroup setting (haplogroup A-I and W-Z) according to suggestion based on a whole mitochondrial genome study [7]. Haplotype distribution (Table 6) shows that out of these six haplogroups, there were four, including $\mathrm{A}, \mathrm{B}, \mathrm{D}$, and $\mathrm{E}$, being shared among different varieties, while haplogroups $\mathrm{C}$ and $\mathrm{H}$ were each represented by only single individual of DA and LK, respectively. Haplogroups $\mathrm{A}$ and $\mathrm{B}$ were the first and second major haplogroups representing the studied populations at frequencies of $35.45 \%$ and $42.27 \%$, respectively. The frequency of haplogroup D was $10.45 \%$, which was comparable to that of haplogroup E, $10.91 \%$. 


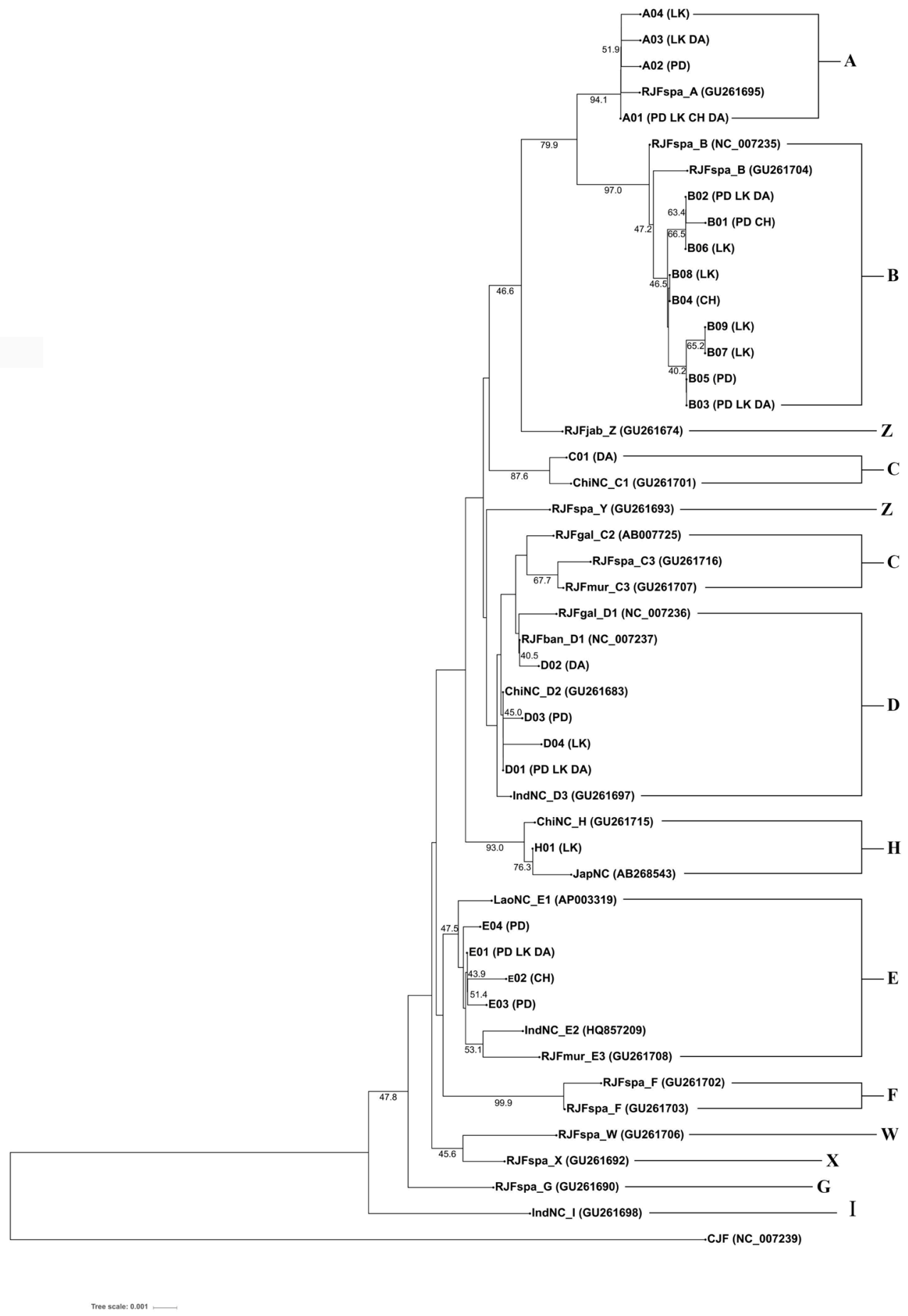

Figure 1. Evolutionary relationships of taxa. The evolutionary history of the 4 Thai indigenous chicken varieties, Pra-dhu-hang-dam (PD), Leung-hang-khao (LK), Chee (CH), and Dang (DA) was inferred using the Neighbor-Joining method. The percentages of replicate trees in which the associated taxa clustered together in the bootstrap test (1,000 replicates) are displayed next to the branches. Bootstrap values lower than $40 \%$ are not shown. Evolutionary analyses were conducted in MEGA6. Data were grouped into 13 haplogroups (A-I and W-Z) as suggested by Miao et al [7].

The majority of the $\mathrm{PD}$ and $\mathrm{CH}$ representative populations were clustered in haplogroup $\mathrm{B}$, and that of LK and DA were in haplogroup A with frequencies of $53.75 \%$ and $67.65 \%$, and $42.11 \%$ and $56.67 \%$, respectively. The second major haplogroup of the PD and $\mathrm{CH}$ was haplogroup A being accounted re- spectively for $28.75 \%$ and $17.65 \%$ while that of LK and DA was haplogroup B for $27.63 \%$ and $20 \%$.

Most of PD individuals were in haplotype B01 (31.25\%) then followed by haplotypes A01, B02, and A02 which represented $18.75 \%, 15.0 \%$, and $10 \%$ of this variety, respectively. 
Table 6. Distribution of mtDNA D-loop haplotypes in four varieties of Thai indigenous chickens

\begin{tabular}{|c|c|c|c|c|c|c|}
\hline Clade & Haplotype & PD & LK & $\mathrm{CH}$ & DA & Total \\
\hline \multirow[t]{4}{*}{ A } & A01 & 15 & 25 & 6 & 13 & 59 \\
\hline & $\mathrm{A} 02$ & 8 & - & - & - & 8 \\
\hline & $\mathrm{A} 03$ & - & 2 & - & 4 & 6 \\
\hline & $\mathrm{A} 04$ & - & 5 & - & - & 5 \\
\hline \multirow[t]{9}{*}{ B } & B01 & 25 & - & 19 & - & 44 \\
\hline & $\mathrm{B} 02$ & 12 & 15 & - & 2 & 29 \\
\hline & B03 & 4 & 2 & - & 4 & 10 \\
\hline & B04 & - & - & 4 & - & 4 \\
\hline & B05 & 2 & - & - & - & 2 \\
\hline & B06 & - & 1 & - & - & 1 \\
\hline & B07 & - & 1 & - & - & 1 \\
\hline & B08 & - & 1 & - & - & 1 \\
\hline & B09 & - & 1 & - & - & 1 \\
\hline C & $\mathrm{CO}$ & - & - & - & 1 & 1 \\
\hline \multirow[t]{4}{*}{$D$} & D01 & 7 & 9 & - & 3 & 19 \\
\hline & D02 & - & - & - & 2 & 2 \\
\hline & D03 & 1 & - & - & - & 1 \\
\hline & D04 & - & 1 & - & - & 1 \\
\hline \multirow[t]{4}{*}{$E$} & E01 & 3 & 12 & - & 1 & 16 \\
\hline & E02 & - & - & 5 & - & 5 \\
\hline & E03 & 2 & - & - & - & 2 \\
\hline & E04 & 1 & - & - & - & 1 \\
\hline $\mathrm{H}$ & $\mathrm{H} 01$ & - & 1 & - & - & 1 \\
\hline Total & & 80 & 76 & 34 & 30 & 220 \\
\hline
\end{tabular}

PD, Pra-dhu-hang-dam; LK, Leung-hang-khao; CH, Chee; DA, Dang.

Other haplotypes expressed in the PD group, including B03, B05, D01, D03, E01, E03, and E06 each accounted for less than $10 \%$. The haplotypes of LK individuals with frequencies higher than 10\% were A01 (32.89\%), B02 (19.74\%), E01 (15.79\%), and D01 (11.84\%) while A03 and A04 were represented by less than $10 \%$ of this population. The remaining haplotypes including B03, B06, B08, B09, D04, and H01 were each represented by only a single individual. $\mathrm{CH}$ individuals were distributed in four haplotypes of which more than half of the samples were in haplotype B02 (55.88\%). A01, E02, and B04 haplotypes were accounted for $17.65 \%, 14.71 \%$, and $11.76 \%$ of the $\mathrm{CH}$ representative population, respectively. Most of DA individuals were in haplotype A01 (43.33\%), and then followed by an equal frequency of $13.33 \%$ in haplotype A03 and B03 and 10\% in D01. The rest were dispersed in four haplotypes (B02, C01, D02, and E01) with frequencies of less than $10 \%$ each.

\section{DISCUSSION}

Chicken domestication has been practiced worldwide for consumption, companionship and entertainment. Human migration introduces a long-distance gene flow and enables genetic material exchanges among chickens of different ori- gins $[6,13]$. Exploration of background genetic relationships among chickens in the region might provide traits of humanchicken, human-human and chicken-chicken interactions going on since the prehistoric era and could lead to the identification of an ancestral area as a center of chicken domestication $[20,21]$. This study presents molecular genetic evidences in supporting the illustration of matrilineal characters and genetic diversity of Thai indigenous chickens as well as their genetic relationships with RJF and other potential associated indigenous chickens.

As revealed by the $\mathrm{NJ}$ tree (Figure 1), the 4 Thai indigenous chicken varieties were each distributed in 3 to 5 haplogroups, indicating the existence of a contribution of multiple maternal lineages in all varieties. Each haplogroup was also found representing more than 1 variety, which could suggest that they are derived from common maternal ancestors. All 5 haplogroups are as well represented by RJF, enforcing the role of the RJF as the ancestor of domestic chickens including the Thai indigenous varieties.

The maternal lineage sharing has been reported among different indigenous chicken breeds of various geographical locations $[4,8,22]$. Identical sequences expressed as the same haplotype of some individuals of different breed/varieties are presented in this study that is in line with other reports [6]. Domestic chickens are therefore suggested to be in close genetic relationships regardless of distinctive phenotypes and physiological/reproductive performance.

Hybridization among chicken breeds with the same or different locality of origin, besides coincident mutations could also be the explanations to the findings above mentioned. Fighting chickens, originally inhabited in Southeast Asia including Thailand, have been commonly crossbred with the expectation of superior performance through hybrid vigor. A trace of this domestication effect could be present in the background genetic relationships among chicken populations. Although, we collected the samples from standard genetic stocks of the Department of Livestock Development of Thailand to ensure their purebred status, breed separation of these indigenous chickens might not have been long enough to express a breed-specific haplogroup in phylogenetic relationship analysis of D-loop mtDNA (Figure 1), which is similar to negative findings in other reports [6].

Non-significant Tajima's D being observed in all studied populations of Thai indigenous chickens (Table 3) signified that they were consistent with a population at mutation-drift equilibrium [23], thereby suggesting neutral selection is involved. The indigenous chickens have been generally raised as free-range backyard flocks in which random mating is permitted without farmer's interest in programmed breeding. The tropical to subtropical environment is also suitable for these chickens to survive and reproduce. Thus, impacts of selection pressures either natural or man-made are less likely applied 
on these populations, which supports the neutrality found. AMOVA results (Table 4) suggested that the main contribution to the genetic variance was due to variation within populations. Pairwise genetic relationship as determined by $\mathrm{F}_{\mathrm{ST}}$ (Table 5) indicated the highest intimacy between DA and LK (0.00879), while $\mathrm{CH}$ was closely genetically related with PD (0.02276). Significant genetic variation (0.24882) between $\mathrm{CH}$ and DA was the highest compared to others. It should be noted that $\mathrm{DA}$ and $\mathrm{CH}$ are less popular among Thai farmers compared to the other two varieties, which are distributed in all parts of the country. DA has been mostly raised in the south while $\mathrm{CH}$ has been concentrated in the northeast of the country. This separated geographical distribution could lead to a limited gene flow thereby explaining the least genetic relationships found between DA and $\mathrm{CH}$.

Thai indigenous chickens appeared to be dominated by 2 maternal lineages defined in haplogroup A and B, those having distribution in South and Southwest China and surrounding areas and in Southeast Asia [6,7,12]. About 10\% of the Thai indigenous chickens were found in haplogroup $\mathrm{D}$ and $\mathrm{E}$ indicating that this haplogroup also contributed considerably to Thai indigenous chickens. Haplogroup D has been composed of RJF and gamecocks from Indonesia, India, Japan and various indigenous chickens from Africa, South Asia, Southeast Asia and East Asia of which the origin has been presumed to be in Southwest China and/or surrounding region (Vietnam, Myanmar, Thailand, and India) [6,7]. Haplogroup E is mainly distributed in Eurasian and South Asian domestic chickens $[6,7]$. The maternal lineages associated with this haplogroup could have originated from the Indian subcontinent and possibly spread to Southeast Asia [6].

Haplogroup $\mathrm{C}$ and $\mathrm{H}$ were each represented by only one individual of Thai indigenous chicken in this study. Haplogroup C is mainly distributed in East, Southeast and South Asia while haplogroup $\mathrm{H}$ has originated in Southwest China and Japan [7]. The haplogroup $\mathrm{H}$ is a rare clade with only a few members of gamecocks cited, including Chinese Chigulu and Japanese Shamo breeds [5,7] to which Thai indigenous chickens are added according to this study. Gamecocks of Southeast Asia have been documented as the origin of Okinawa Shamo gamecocks of Japan [24], which were speculated to play a key role as founder of Japanese domestic chickens [25]. On the contrary, Oka et al [5] suggested that this haplogroup which was referred as haplogroup $\mathrm{F}$ is isolated to only Okinawa Shamo and has no relationships with other Japanese domestic chickens. Both Southeast Asia and China have been suggested as centers for chicken domestication [2,5], it is therefore interesting to further explore the origin and development of this haplogroup as well as to decipher the relationships between Thais as Southeast Asian chickens and Chinese chickens. Nevertheless, haplogroup $\mathrm{H}$ is not documented as being in any of the junglefowl. This leaves the ancestor and domesti- cation origin of this clade inconclusive, thereby requiring further scrutiny.

In summary, this study suggested that Thai indigenous chickens including DA, $\mathrm{CH}, \mathrm{PD}$, and $\mathrm{LK}$ are likely to be descended from a common ancestor, the RJF, with multiple matrilineal contributions. The populations were under genetic equilibrium and their genetic variations were mainly under the control of within-population variation. D-loop nucleotide polymorphism appeared to lack breed specific information in this regard.

\section{CONFLICT OF INTEREST}

We certify that there is no conflict of interest with any financial organization regarding the material discussed in the manuscript.

\section{ACKNOWLEDGMENTS}

This study was carried out under the financial support of Biodiversity-Based Economy Development Office, BEDO (Public Organization). Supports for research facilities and research assistantships were provided by Kasetsart University through Human-Chicken Multi-relationships Research (HCMR) project and by the Center of Excellence on Agricultural Biotechnology, Science and Technology Postgraduate Education and Research Development Office, Office of Higher Education Commission, Ministry of Education (AG-BIO/PERDO-CHE). Samples were kindly supported by Chiangmai, Nongkwang, Krabinburi, Thapra and Suratthani Livestock Research and Breeding Centers, Department of Livestock Development of Thailand.

\section{REFERENCES}

1. Darwin C. The variation of animals and plants under domestication. 1st ed. London, UK: John Murray; 1868.

2. Fumihito A, Miyake T, Sumi S, et al. One subspecies of the red junglefowl (Gallus gallus gallus) suffices as the matriarchic ancestor of all domestic breeds. Proc Natl Acad Sci USA 1994; 91:12505-9.

3. Fumihito A, Miyake T, Takada M, et al. Monophyletic origin and unique dispersal patterns of domestic fowls. Proc Natl Acad Sci USA 1996;93:6792-5.

4. Liu ZG, Lei CZ, Luo J, et al. Genetic variability of mtDNA sequences in Chinese native chicken breeds. Asian-Australas J Anim Sci 2004;17:903-9.

5. Oka T, Ino Y, Nomura K, et al. Analysis of mtDNA sequences shows Japanese native chickens have multiple origins. Anim Genet 2007;38:287-93.

6. Liu YP, Wu GS, Yao YG, et al. Multiple maternal origins of chickens: out of the Asian jungles. Mol Phylogenet Evol 2006; 38:12-9.

7. Miao YW, Peng MS, Wu GS, et al. Chicken domestication: 
an updated perspective based on mitochondrial genomes. Heredity 2013;110:277-82.

8. Hoque MR, Seo DW, Jo C, et al. Reconstruction of phylogenetic relationships of korean chickens using mitochondrial D-loop sequences. J Fac Agr, Kyushu Univ 2013;58:287-93.

9. Kanginakudru S, Metta M, Jakati RD, Nagaraju J. Genetic evidence from Indian red jungle fowl corroborates multiple domestication of modern day chicken. BMC Evol Biol 2008; 8:174.

10. Muchadeyi FC, Eding H, Simianer H, et al. Mitochondrial DNA D-loop sequences suggest a Southeast Asian and Indian origin of Zimbabwean village chickens. Anim Genet 2008;39: 615-22.

11.Sulandari SRI, Zein MSA, Sartika T. Molecular characterization of Indonesian indigenous chickens based on mitochondrial DNA Displacement (D)-loop sequences. HAYATI J Biosci 2008;15:145-54

12. Kawabe K, Worawut R, Taura S, et al. Genetic diversity of mtDNA D-loop polymorphisms in laotian native fowl populations. Asian-Australas J Anim Sci 2014;27:19-23.

13. Cuc NTK, Simianer H, Groeneveld LF, Weigend S. Multiple maternal lineages of vietnamese local chickens inferred by mitochondrial DNA D-loop sequences. Asian-Australas J Anim Sci 2011;24:155-61.

14. Brown WM, Matthew George J, Wilson AC. Rapid evolution of animal mitochondrial DNA. Proc Natl Acad Sci USA 1979; 76:1967-71.

15. Osman SAM, Nishibori M. Phylogenetic analysis of South East Asian countries chickens based on mitochondrial DNA variations. J Poult Sci 2014;51:248-61.
16. Nishibori M, Hayashi T, Tsudzuki M, Yamamoto Y, Yasue H. Complete sequence of the Japanese quail (Coturnix japonica) mitochondrial genome and its genetic relationship with related species. Anim Genet 2001;32:380-5.

17.Librado P, Rozas J. DnaSP v5: a software for comprehensive analysis of DNA polymorphism data. Bioinformatics 2009;25: 1451-2.

18. Excoffier L, Lischer HE. Arlequin suite ver 3.5: a new series of programs to perform population genetics analyses under Linux and Windows. Mol Ecol Resour 2010;10:564-7.

19. Tamura K, Stecher G, Peterson D, Filipski A, Kumar S. MEGA6: molecular evolutionary genetics analysis version 6.0. Mol Biol Evol 2013;30:2725-9.

20. Bhuiyan MS, Chen S, Faruque S, Bhuiyan AK, Beja-Pereira A. Genetic diversity and maternal origin of Bangladeshi chicken. Mol Biol Rep 2013;40:4123-8.

21.Silva P, Guan X, Ho-Shing O, et al. Mitochondrial DNA-based Analysis of genetic variation and relatedness among Sri Lankan indigenous chickens and the Ceylon junglefowl (Gallus lafayetti). Anim Genet 2009;40:1-9.

22.Liao Y, Mo G, Sun J, Wei F, Liao DJ. Genetic diversity of Guangxi chicken breeds assessed with microsatellites and the mitochondrial DNA D-loop region. Mol Biol Rep 2016;43:415-25.

23. Kimura M. The neutral theory of molecular evolution. Cambridge, UK: Cambridge University Press; 1983.

24. Komiyama T, Ikeo K, Gojobori T. Where is the origin of the Japanese gamecocks? Gene 2003;317:195-202.

25. Komiyama T, Ikeo K, Tateno Y, Gojobori T. Japanese domesticated chickens have been derived from Shamo traditional fighting cocks. Mol Phylogenet Evol 2004;33:16-21. 